\title{
The effect of heat transfer on the polarizations within an intermediate temperature solid oxide fuel cell
}

\author{
M. Navasa, M. Andersson, J. Yuan \& B. Sundén \\ Department of Energy Sciences, Lund University, Sweden
}

\begin{abstract}
Solid oxide fuel cells (SOFCs) are promising candidates for future energy systems due to their ability to use renewable fuels and that they are energy efficient. A fully coupled two-dimensional computational fluid dynamics (CFD) model based on the finite element method (using COMSOL Multiphysics) is developed to describe an intermediate temperature SOFC single cell. Governing equations for various transport processes including heat, mass, momentum and charge transport (ion and electron) are implemented and coupled with the chemical and electrochemical reactions that take place inside the cell.

The chemical and electrochemical reactions are strongly bonded to heat transfer being special contributors to the global and local energy balances of the cell. Thus, the effect of methane in the fuel composition on the reaction rate focusing on the polarizations is studied. When considering a mixture of carbon monoxide and hydrogen as the electrochemically active fuels, a lower open circuit voltage is observed, which means lower activation polarizations, increased reaction rates and an increase in the temperature difference of the whole cell unit. Consequently, by reducing the methane concentration, less methane steam reforming is required which leads to a higher cell temperature difference increasing the electrochemical reaction rate. Nevertheless, high temperature gradients introduce mechanical stresses and material degradation which may cause cell failure.

Keywords: SOFC, CFD, fuel, carbon monoxide, hydrogen, activation polarizations, current density.
\end{abstract}




\section{Introduction}

Solid oxide fuel cells (SOFCs) are electrochemical devices operating at high temperatures and converting the chemical energy of fuels directly into electrical energy in an environmental friendly and efficient manner compared to conventional power generation systems. Thus, SOFCs are regarded as promising candidates for energy conversion and for being capable to obtain electrical power for our society in a clean and efficient way.

When comparing SOFCs to other current fuel cell types, SOFCs present a number of attractive features. One of the most important ones is that SOFCs are fuel flexible mainly due to the high operating temperatures. This means that different fuels apart from pure hydrogen can be used due to the tolerance of carbon monoxide (CO). Apart from fuel flexibility, the high tolerance to possible contaminants compared to other fuel cells and the possibility to reform the fuel internally makes them promising candidates as renewable energy equipment.

\section{Problem statement}

The high operating temperature allows SOFCs to run under different alternative fuels, compared to pure hydrogen, which is a great advantage due to the high flammability and volatility of hydrogen as it becomes difficult to store or handle. Moreover, pure hydrogen is expensive to obtain because it must be obtained from another source, usually methane, and it requires special storing and handling conditions.

Different alternative fuels seem to be suitable for SOFCs due to the high operating temperatures. Although methane is the most commonly used fuel, methanol, ethanol or ethane among others seem to be suitable candidates. Despite being carbonated fuels, $\mathrm{CO}_{2}$ emissions should not be a matter of concern as these fuels can be produced in a renewable manner (biogas, etc.). The net effect of the emissions will then be zero [1].

However, less importance is given to carbon monoxide $(\mathrm{CO})$ as it is usually part of the fuel or a product from the methane steam reforming. It is usually considered to be consumed during the water-gas shift reaction. Anyhow, $\mathrm{CO}$ is also oxidized at the anode of the cell and this electrochemical reaction is commonly omitted despite the fact that $\mathrm{CO}$ affects the open circuit voltage and the polarization losses.

The main objective of this article is to describe the effects of the CO concentration from the chemical reactions that take place in the SOFCs on the polarizations in an intermediate temperature fuel cell. Thus, a numerical study considering two types of fuel, one with pre-reformed natural gas and another one without methane, i.e., only $\mathrm{CO}, \mathrm{H}_{2}, \mathrm{H}_{2} \mathrm{O}$ and $\mathrm{CO}_{2}$, will be performed.

\section{Heat generation/consumption and transfer within an SOFC}

Heat transfer within the whole FC unit cell consists of convection and conduction. Convection occurs between the flowing gas and the solid surfaces while conduction 
takes place in the solid and in the porous parts. Moreover, thermal radiation also takes place within the electrode-electrolyte structure, from the stack to the surrounding environment and surface to surface radiation in the air and fuel channels. Nevertheless, considering radiation in the model adds a higher degree of complexity to the governing equations [2]. Heat generation or consumption is also present due to different sources but especially, in the chemical and electrochemical reactions. The different heat sources will be further described. The general heat conduction equation is used to calculate the temperature distribution for the solid phase in the porous electrodes [3]:

$$
\nabla\left(-k_{s} \cdot \nabla T_{s}\right)=Q_{s}
$$

where $Q_{s}$ is the heat transfer between the gas and the solid phases, and the heat generation due to the ohmic polarization and the internal reforming reactions.

The temperature for the gas phase in the porous electrodes (also valid for the air and fuel channels) is governed by [3]:

$$
\nabla\left(-k_{g} \cdot \nabla T_{g}\right)=Q_{g}-\rho_{g} c_{p, g} u \nabla T_{g}
$$

where $k_{g}$ is the gas thermal conductivity and $Q_{g}$ is the heat transfer between the gas and the solid phases which is calculated as follows:

$$
Q_{g}=-Q_{s}=h_{v}\left(T_{g}-T_{s}\right)=A v h_{s, g, p o r}\left(T_{g}-T_{s}\right)
$$

the subscript $s$ refers to solid, $g$ to gas and por to porous. All previous equations are based on the local temperature non-equilibrium (LTNE) approach where the temperature from the gas- and solid-phases are not assumed to be locally the same. Nevertheless, in the current model, the local temperature equilibrium (LTE) approach is used [4]. For the LTE approach, the heat governing equation is defined as in 4 but this is reduced to 1 for pure heat conduction in the electrolyte and interconnects [4].

$$
\rho_{g} \epsilon c_{p, g} \vec{u} \nabla T=\nabla \cdot\left(k_{e f f} \nabla T\right)+Q
$$

There are different mechanisms of heat generation or consumption taking place in an SOFC. But, the main contributors are the electrochemical and the chemical reactions within the SOFC. Thus, knowledge about these sources is of interest as it can provide information for the overall performance, possible mechanical stresses, etc. The mentioned heat sources will be described in the following sections.

\subsection{Methane steam reforming and water-gas shift reforming reactions}

SOFCs using methane as a fuel need a reformation process of the fuel as methane should not be directly used as fuel because of a very slow electrochemical reaction rate and mainly due to carbon deposition in the anode. Thus, by reforming the methane, carbon monoxide and hydrogen are produced which can now be directly used as fuel. The reforming process can be done internally or externally but SOFCs present the possibility to have internal reforming reactions of methane due to 
the high operating temperatures. The methane steam reforming (MSR) reaction, eqn (5), is a highly endothermic reaction $\left(\Delta H_{1273 K}=227.6 \mathrm{~kJ} \mathrm{~mol}^{-1}\right)$ and thus, introduces a high sink of heat into the cell components involved in the process [5]. Steam reforming reaction of methane takes place in the anode of the fuel cell as it requires the nickel particles which act as catalysts of the reaction. Thus, the steam reforming reaction strictly takes place at the Ni particles' surface.

$$
\mathrm{CH}_{4}+\mathrm{H}_{2} \mathrm{O} \rightleftharpoons 3 \mathrm{H}_{2}+\mathrm{CO}
$$

As the MSR reaction is endothermic, the heat absorbed or consumed by the reaction in $\frac{\mathrm{W}}{\mathrm{m}^{2}}$ can be determined by the reaction rate and the enthalpy change of reaction.

$$
Q_{M S R}^{\prime \prime \prime}=r_{M S R} \Delta H_{M S R} A v^{a n}
$$

Anyhow, the MSR reaction of methane is accompanied by the water-gas shift (WGS) reaction. The WGS is slightly exothermic $\left(\Delta H_{1273 K}=-31.8 \mathrm{~kJ} \mathrm{~mol}^{-1}\right)$ and it is usually assumed to be in equilibrium as it is a much faster reaction than the $\mathrm{SR}$ reaction [5-9].

$$
\mathrm{CO}+\mathrm{H}_{2} \mathrm{O} \rightleftharpoons \mathrm{CO}_{2}+\mathrm{H}_{2}
$$

The heat generated by the WGS reaction can be expressed as follows.

$$
Q_{W G S}^{\prime \prime \prime}=r_{W G S} \Delta H_{W G S} A v^{a n}
$$

\subsection{Electrochemical reactions}

The oxidation of hydrogen is the driving reaction of the energy conversion in an SOFC device. This process can be written as a general reaction as follows:

$$
\mathrm{H}_{2}+\frac{1}{2} \mathrm{O}_{2} \rightleftharpoons \mathrm{H}_{2} \mathrm{O}
$$

Nevertheless, this general electrochemical reaction consists of two semireactions that take place in different parts of the fuel cell. The reduction of oxygen, eqn (10), takes place in the active layer of the triple-phase boundaries (TPBs) of the cathode while the oxidation of hydrogen, eqn (11), takes place at the anodic TPBs.

$$
\begin{gathered}
\frac{1}{2} \mathrm{O}_{2}+2 e^{-} \rightarrow \mathrm{O}^{2-} \\
\mathrm{H}_{2}+\mathrm{O}^{2-} \rightarrow \mathrm{H}_{2} \mathrm{O}+2 e^{-}
\end{gathered}
$$

However, another electrochemical reaction takes place in the anodic TPBs if CO is present. This reaction is the oxidation of carbon monoxide to carbon dioxide which is of special interest when considering the carbon monoxide as a reactant as well. Note that $\mathrm{CO}$ also reacts with water in the WGS reaction.

$$
\mathrm{CO}+\mathrm{O}^{2-} \rightarrow \mathrm{CO}_{2}+2 e^{-}
$$

As mentioned previously, the global electrochemical reaction for $\mathrm{H}_{2}$ is highly exothermic $\left(\Delta H_{1273 K}=-250 \mathrm{~kJ} \mathrm{~mol}^{-1}\right)$ but only a part can be converted into 
electric work. The maximum work that can be obtained is given by the Gibbs free energy $(\Delta G)$.

$$
\Delta G_{E R}=\Delta H_{E R}-T \Delta S_{E R}
$$

where the subscript $E R$ refers to electrochemical reaction and the term $\left(-T \Delta S_{E R}\right)$ is the entropy change related to the heat due to the electrochemical reaction.

Despite the fact that most global models assume that the heat associated with the general electrochemical reaction is assigned to the anodic TPB, this heat is generated at the two different electrodes and in different amounts. Therefore, a detailed model should take into account the entropy changes for each semi-reaction and thus, calculate the heat generation due to the electrochemical reactions for each electrode as follows. However, one must consider the reaction sites and thus, the released heat per unit volume $\left[\frac{\mathrm{W}}{\mathrm{m}^{3}}\right]$, by considering TPBs reaction area, can be calculated as follows [5].

$$
Q_{E R}^{\prime \prime \prime a n, c a t}=\frac{j}{2 F}\left(-T \Delta S_{E R}^{a n, c a t}\right) A v^{a n, c a t}
$$

where $j$ is the local current density. Moreover, Fischer and Seume [5] showed that the heat released or absorbed by the semi-reactions are the most important sources or sinks of heat in the fuel cell.

The local current density has different expressions for the cathode and for the anode. Besides, it is calculated separately for hydrogen and carbon monoxide at the anode side according to an approach developed by Suwanwarangkul et al. [10]. This approach assumes that the rate of $\mathrm{CO}$ oxidation reaction is 2.5 times lower than for the $\mathrm{H}_{2}$ oxidation reaction, i.e., $j_{\mathrm{H}_{2}}^{a n}=2.5 j_{C O}^{c a t}$ because the $\mathrm{CO}$ oxidation presents a much higher overpotential than for the $\mathrm{H}_{2}$ oxidation reaction for the same current density [11]. Notice the partial pressure terms for this electrochemical approach which are frequently neglected within the open literature.

$$
\begin{gathered}
j^{c a t}=\frac{0.25 \cdot 10^{10} \exp \left(\frac{-130000}{R T}\right) R T \sqrt{P_{\mathrm{O}_{2}}}}{F} . \\
j_{\mathrm{H}_{2}}^{a n}=\frac{2.1 \cdot 10^{11} \exp \left(\frac{-120000}{R T}\right) R T P_{\mathrm{H}_{2} \mathrm{O}}^{0.266}}{\left.F\left(\frac{-2 F \eta_{a c t}^{c a t}}{R T}\right)-\exp \left(\frac{2 F \eta_{a c t}^{c a t}}{R T}\right)\right]} \\
{\left[\operatorname { e x p } \left(\frac{\left.\left.2 F \eta_{a c t, \mathrm{H}_{2}}^{a n} P_{\mathrm{H}_{2}}\right)^{0.266}-\exp \left(\frac{-F \eta_{a c t, \mathrm{H}_{2}}^{a n}}{R T}\right)\right]}{R T} .\right.\right.} \\
j_{\mathrm{CO}}^{a n}=\frac{0.84 \cdot 10^{11} \exp \left(\frac{-120000}{R T}\right) R T P_{\mathrm{CO}}^{0.266}}{F\left(K_{e q, \mathrm{CO}} P_{\mathrm{CO}}\right)^{0.266}} . \\
{\left[\exp \left(\frac{2 F \eta_{a c t, \mathrm{CO}}^{a n}}{R T}\right)-\exp \left(\frac{-F \eta_{a c t, \mathrm{CO}}^{a n}}{R T}\right)\right]}
\end{gathered}
$$


where $K_{e q}$ is the temperature dependent equilibrium constant for the electrochemical reactions of hydrogen and carbon monoxide, respectively.

The two electrochemical fuels, $\mathrm{H}_{2}$ and $\mathrm{CO}$, are treated as two resistances in parallel. Thus, the total local current density for the anode is calculated as the sum of the hydrogen and carbon monoxide anodic current densities.

$$
j^{a n}=j_{\mathrm{H}_{2}}^{a n}+j_{\mathrm{CO}}^{a n}
$$

Moreover, the actual cell voltage for this case is related to the open circuit voltage, also known as Nernst potential $\left(E^{O C V}\right)$ [12], and to the different polarizations as it follows.

$$
\begin{aligned}
& V=E_{\mathrm{H}_{2} / \mathrm{O}_{2}}^{O C V}-\eta_{a c t, \mathrm{O}_{2}}-\eta_{a c t, \mathrm{H}_{2} / \mathrm{H}_{2} \mathrm{O}}-\eta_{c o n c, \mathrm{O}_{2}}-\eta_{c o n c, \mathrm{H}_{2} / \mathrm{H}_{2} \mathrm{O}}-\sum \eta_{\Omega} \\
& V=E_{\mathrm{CO} / \mathrm{O}_{2}}^{O C V}-\eta_{a c t, \mathrm{O}_{2}}-\eta_{a c t, \mathrm{CO} / \mathrm{CO}_{2}}-\eta_{c o n c, \mathrm{O}_{2}}-\eta_{c o n c, \mathrm{CO} / \mathrm{CO}_{2}}-\sum \eta_{\Omega}
\end{aligned}
$$

\subsection{Concentration polarizations}

Concentration polarizations are those polarizations associated with the variation of concentration of the critical species due to mass transfer processes. There are basically two main sources due to mass transport: transport of reactants and products through the electrodes and diffusion between the bulk flows and cell surfaces. Thus, concentration polarizations are highly dependent on the diffusion length, the pore volume percentage of the components as well as the gases involved [13]. Therefore, these concentration polarizations give a surplus heat at the anodic and cathodic reaction sites which can be calculated as follows $\left[\frac{\mathrm{W}}{\mathrm{m}^{3}}\right][5]$.

$$
Q_{\text {conc }}^{\prime \prime \prime} \text {, cat }=j \eta_{\text {conc }}^{a n, c a t} A v^{a n, c a t}
$$

The concentration polarizations used are specified from [14] and are calculated separately for the cathode and the $\mathrm{CO}$ and $\mathrm{H}_{2}$ in the anode. However, the concentration polarization for the carbon monoxide is pointed out.

$$
\eta_{c o n c, \mathrm{CO}}^{a n}=\frac{R T}{n_{e}^{a n} F} \ln \left(\frac{P_{\mathrm{CO}_{2}, T P B} P_{\mathrm{CO}, b}}{P_{\mathrm{CO}, T P B} P_{\mathrm{CO}_{2}, b}}\right)
$$

where $n_{e}$ is the number of electrons involved, $P_{i, T P B}$ the partial pressure of component $i$ at the TPB and $P_{i, b}$ is the partial pressure of component $i$ at the interface between the electrode and the gas channel.

\subsection{Activation polarizations}

The activation polarizations can be considered as the extra potential needed in order to overcome the activation energy $\left(E_{A}\right)$ or energy barrier of the ratedetermining step to a value that the reaction proceeds at a desired rate $[4,5,13]$. 
The heat generated by these irreversible polarizations is released at the anodic and cathodic catalyst particle surfaces. Thus, the heat source will be $\left[\frac{\mathrm{W}}{\mathrm{m}^{3}}\right][5]$.

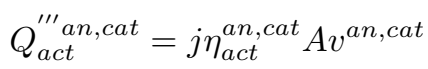

The local current densities can be obtained through eqns (15)-(17).

\subsection{Ohmic polarizations}

The ohmic polarizations are due to the joule heating effect or, in other words, they are due to the resistance to ion transfer through the electrolyte, electron transfer through the electrodes and current collectors and also by the contact resistance between the different cell components. Thus, they are characteristic for the solid parts of the FC and they lead to a release of heat which can be determined by the local current density and the material conductivity $[4,5,13]$. The electric conductivities used can be found in [4].

$$
Q_{\Omega}^{\prime \prime \prime}=\frac{1}{\sigma} j^{2}
$$

where $Q_{\Omega}^{\prime \prime \prime}$ is the local heat source $\left[\frac{\mathrm{W}}{\mathrm{m}^{3}}\right]$.

\section{Simulation results and discussion}

The model relies on the experimental data from a standard cell developed at NIMTE in China. A cell voltage of $0.7 \mathrm{~V}$ is assumed, the inlet temperatures of the fuel and air flows are set to $980 \mathrm{~K}$ and co-flow is applied in the model. Specific details of this model can be found in Andersson [4] except those details concerning the $\mathrm{CO}$ electrochemical reaction. Simulations are performed using COMSOL Multiphysics.

The ion current density as well as the activation polarizations in the main flow direction have been calculated for two types of fuel when considering the electrochemical reaction of CO. The molar flow rate distribution is also shown. The first fuel, or the base fuel, consists of 30\% pre-reformed natural gas as defined by the International Energy Agency (IEA) with an $18 \%$ oxygen utilization and a $70 \%$ fuel utilization. The second fuel consists of a mixture of $25 \%$ molar of each reactant: $\mathrm{CO}, \mathrm{H}_{2} \mathrm{O}, \mathrm{CO}_{2}$ and $\mathrm{H}_{2}$. Moreover, the same amount of fuel, in terms of hydrogen equivalents, and oxygen as in the first fuel is supplied. Thus, the utilizations for this fuel are not directly specified.

The ion current density along the flow direction is shown in Figure 1. In Figure 1a, the ion current density for the pre-reformed natural gas increases along the flow direction, closer to the inlet, due to the cell temperature increase. However, this increase is limited due to the decrease of the open circuit voltage and the depletion of oxygen and fuel as they react. In Figure 1b, the ion current density for the $\mathrm{CO}$ rich fuel is shown. In this case, a higher maximum ionic current density is achieved compared to the other fuel and this peak is achieved further away from the 


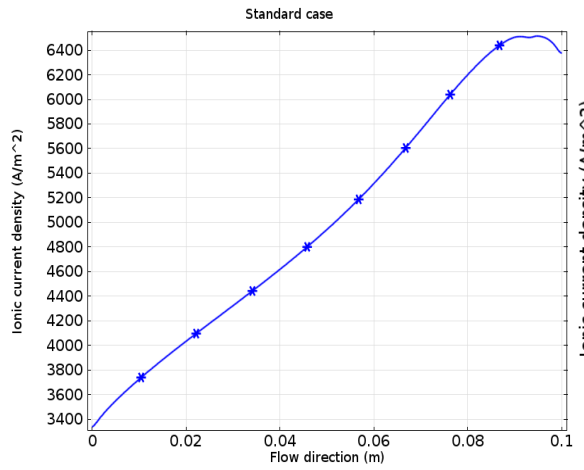

(a) Pre-reformed natural gas fuel

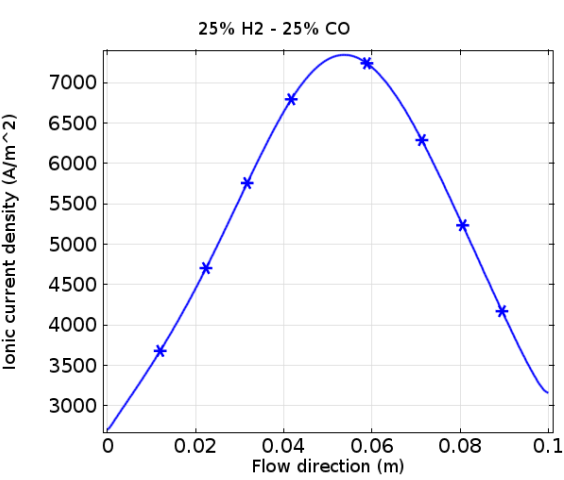

(b) $\mathrm{CO}$ rich fuel

Figure 1: Current density.

cell outlet compared to the pre-reformed fuel. With a higher $\mathrm{CO}$ concentration and no presence of $\mathrm{CH}_{4}$, the outlet temperature is higher as no reforming takes place, which is a strong endothermic reaction. Thus, if the outlet temperature is higher, the reaction rates of the electrochemical reactions increase and the reactions proceed faster. A faster reaction rate results in a faster consumption of fuel and oxygen and the ionic current density peak is achieved earlier compared to the pre-reformed natural gas fuel. Notice that due to the fixed conditions of the same amount of fuel supplied, the fuel and oxygen utilization in the $\mathrm{CO}$ rich fuel is much higher as the ionic current density peak is achieved earlier in the flow direction than for the other fuel. The decrease of the ionic current density is due to the depletion of fuels and the decrease in the open circuit fuel cell voltage due to the increase in temperature. The open circuit cell voltage decreases with a temperature increase if the cell voltage is kept constant as in this case. Nevertheless, it should be pointed out that no SOFC would operate under the conditions of the $\mathrm{CO}$ rich fuel cell due to the high fuel utilization. Thus, it would be needed to decrease the cell voltage or increase the fuel and/or air flow rates. All possibilities must be studied carefully as many parameters are strongly related at the same time. However, the easiest solution would be to increase the air flow rate.

The activation polarizations along the flow direction within the anode for $\mathrm{H}_{2}$ and $\mathrm{CO}$ for both fuel cases are shown in Figure 2. For both cases it is found that the activation polarizations decrease along the flow direction while the temperature increases. With a fixed cell voltage, if the temperature increases, the open circuit cell voltage will decrease and the activation polarizations as well. With a $\mathrm{CO}$ rich fuel, Figure $2 b$, the $\mathrm{CO}$ polarizations in the anode side are higher than the $\mathrm{H}_{2}$ compared to the pre-reformed natural gas fuel, Figure 2a. Moreover, the activation polarization decrease in Figure $2 b$ is steeper than in Figure $2 a$ due to the high 


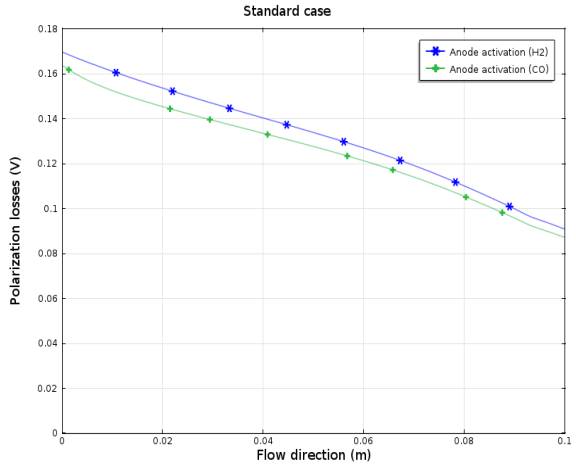

(a) Pre-reformed natural gas fuel

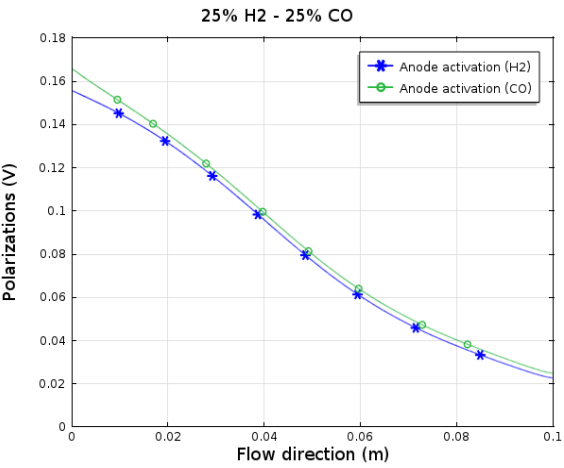

(b) $\mathrm{CO}$ rich fuel

Figure 2: Activation polarizations.

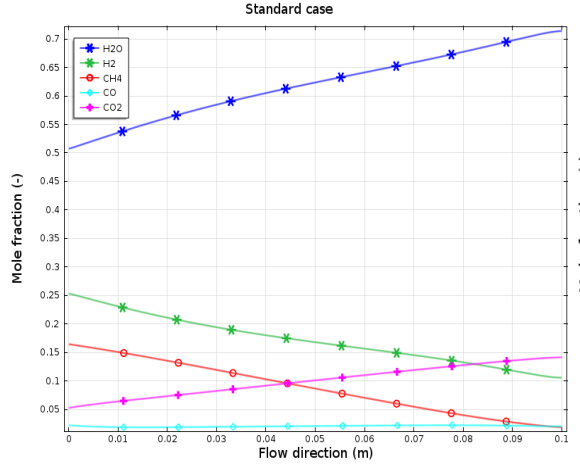

(a) Pre-reformed natural gas fuel

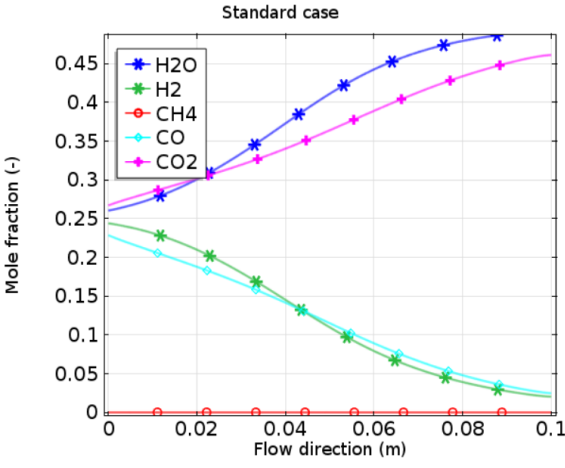

(b) $\mathrm{CO}$ rich fuel

Figure 3: Molar fraction distribution.

temperature achieved and the high fuel utilization. Again, it must be pointed out that this is not an ideal operating condition for an SOFC. In Figure 3, the molar fractions distributions along the flow direction are shown. The main differences are the high $\mathrm{CO}_{2}$ content in the $\mathrm{CO}$ rich fuel, Figure $3 \mathrm{~b}$ and a steeper decrease in the $\mathrm{H}_{2}$ and $\mathrm{CO}$ content . Notice that there is no $\mathrm{CH}_{4}$ in the $\mathrm{CO}$ rich fuel.

\section{Conclusions}

The effect of carbon monoxide as fuel on the activation polarizations on the anode side as well as in the ionic current density is evaluated when the carbon monoxide 
is increased and the methane concentration is decreased taking into account the electrochemical reactions of carbon monoxide and hydrogen simultaneously.

Two different fuels, a pre-reformed natural gas and a carbon monoxide rich fuel, have been used to calculate the activation polarizations as well as the ionic current density along the flow direction. When increasing the carbon monoxide concentration, without the presence of methane, an increase in the cell temperature is observed due to the absence of the reforming reactions. When temperature increases, the ionic current density increases until no reactants are left. When the maximum value is achieved, the ionic current density decreases because of the depletion of fuel. The location of the maximum ionic current density value is given by the fuel utilization of the fuel.

Moreover, a decrease in the activation polarizations in the anode side is also observed with an increase in the carbon monoxide concentration. With a fixed cell voltage, an increase in temperature leads to a decrease in the open circuit cell voltage and consequently, to the activation polarizations. With a higher $\mathrm{CO}$ concentration, the activation polarizations of $\mathrm{CO}$ are higher than the hydrogen activation polarizations while these values are opposite for the pre-reformed fuel. A steep decrease is observed for the $\mathrm{CO}$ rich fuel due to the high fuel utilization. It must be pointed out that a higher air flow rate for the $\mathrm{CO}$ rich fuel case would improve the performance of the cell.

\section{Nomenclature}

$\begin{array}{ll}A v & \text { Active surface area to volume ratio, }\left[\mathrm{m}^{2} \mathrm{~m}^{-3}\right] \\ C_{p} & \text { Specific heat at constant pressure, }\left[\mathrm{kJ} \mathrm{kg}^{-1} \mathrm{~K}^{-1}\right] \\ F & \text { Faraday constant, }\left[\mathrm{sA} \mathrm{mol}{ }^{-1}\right] \\ \Delta G & \text { Gibbs free energy of reaction, }\left[\mathrm{kJ} \mathrm{mol}^{-1}\right] \\ h & \text { Heat transfer coefficient, }\left[\mathrm{W} \mathrm{m}{ }^{-2} \mathrm{~K}^{-1}\right] \\ \Delta H & \text { Enthalpy change of reaction, }\left[\mathrm{kJ} \mathrm{mol}^{-1}\right] \\ j & \text { Current density, }\left[\mathrm{A} \mathrm{m}{ }^{-2}\right] \\ k & \text { Thermal conductivity, }\left[\mathrm{W} \mathrm{m}{ }^{-1} \mathrm{~K}^{-1}\right] \\ k_{i} & \text { Reaction rate constant, }\left[\mathrm{mol} \mathrm{m}^{-3} \mathrm{~Pa}^{-2} \mathrm{~S}^{-1}\right] \\ K_{e q} & \text { Equilibrium constant, dimensionless } \\ n_{e} & \text { Number of electrons, dimensionless } \\ P_{i} & \text { Partial pressure, }[\text { bar }] \text { or }[\mathrm{Pa}]^{\prime \prime} \\ Q^{\prime \prime \prime} & \text { Heat flow per unit volume, }\left[\mathrm{W} \mathrm{m}^{-3}\right] \\ r & \text { Reaction rate, mainly }\left[\mathrm{mol} \mathrm{m}^{-2} \mathrm{~s}^{-1}\right] \\ R & \text { Gas constant, }\left[\mathrm{J} \mathrm{mol}{ }^{-1} \mathrm{~K}^{-1}\right] \\ \Delta S & \text { Entropy of reaction, }\left[\mathrm{J} \mathrm{mol}{ }^{-1} \mathrm{~K}^{-1}\right] \\ T & \text { Temperature, }\left[{ }^{\circ} \mathrm{C}\right] \text { or }[\mathrm{K}]\end{array}$




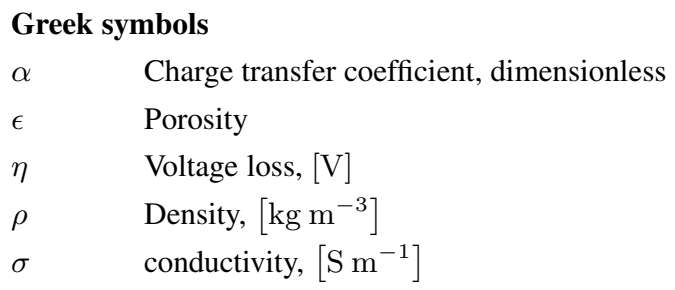

\section{Chemicals}

$\begin{array}{ll}\mathrm{CH}_{4} & \text { Methane } \\ \mathrm{CO} & \text { Carbon monoxide } \\ \mathrm{CO}_{2} & \text { Carbon dioxide } \\ \mathrm{H}_{2} & \text { Hydrogen } \\ \mathrm{H}_{2} \mathrm{O} & \text { Water } \\ \mathrm{Ni} & \text { Nickel } \\ \mathrm{O}_{2} & \text { Oxygen }\end{array}$

\section{Superscripts}

$\begin{array}{ll}\text { an } & \text { Anode } \\ \text { cat } & \text { Cathode } \\ 0 & \text { Standard conditions }\end{array}$

\section{Subscripts}

$\begin{array}{ll}\text { act } & \text { Activation polarizations } \\ \text { conc } & \text { Concentration polarizations } \\ E R & \text { Electrochemical reaction } \\ g & \text { Gas } \\ i & \text { Gas species } \\ \text { por } & \text { Porous } \\ \Omega & \text { Ohmic } \\ 0 & \text { Standard conditions }\end{array}$

\section{Acknowledgements}

The financial support from the European Research Council (ERC-226238MMFCs) and the Swedish Research Council (VR-621-2010-4581) is gratefully acknowledged.

\section{References}

[1] Andersson, M., Paradis, H., Yuan, J. and Sundén, B., Modeling Analysis of Different Renewable Fuels in an Anode Supported SOFC. J Fuel Cell Sci Technol, 8(3), pp. 031013-9, 2011. 
[2] Damm, D.L. and Fedorov, A.G., Radiation heat transfer in sofc materials and components. J Power Sources, 143(1-2), pp. 158-165, 2005.

[3] Sohn, S., Nam, J.H., Jeon, D.H. and Kim, C.J., A micro/macroscale model for intermediate temperature solid oxide fuel cells with prescribed fullydeveloped axial velocity profiles in gas channels. Int J Hydrogen Energ, 35(21), pp. 11890-11907, 2010.

[4] Andersson, M., Solid Oxide Fuel Cell Modeling at the Cell Scale Focusing on Species, Heat, Charge and Momentum Transport as well as the Reaction Kinetics and Effects. Doctoral dissertation, Lund University, 2011.

[5] Fischer, K. and Seume, J.R., Location and magnitude of heat sources in solid oxide fuel cells. J Fuel Cell Sci Technol, 6(1), p. 011002, 2009.

[6] Lehnert, W., Meusinger, J. and Thom, F., Modelling of gas transport phenomena in SOFC anodes. J Power Sources, 87(1-2), pp. 57-63, 2000.

[7] Klein, J.M., Bultel, Y., Georges, S. and Pons, M., Modeling of a SOFC fuelled by methane: From direct internal reforming to gradual internal reforming. Chem Eng Sci, 62(6), pp. 1636-1649, 2007.

[8] Haberman, B.A. and Young, J.B., Three-dimensional simulation of chemically reacting gas flows in the porous support structure of an integratedplanar solid oxide fuel cell. Int J Heat Mass Transfer, 47(17-18), pp. 36173629, 2004.

[9] Aguiar, P., Adjiman, C.S. and Brandon, N.P., Anode-supported intermediate temperature direct internal reforming solid oxide fuel cell. i: model-based steady-state performance. J Power Sources, 138(1-2), pp. 120-136, 2004.

[10] Suwanwarangkul, R., Croiset, E., Entchev, E., Charojrochkul, S., Pritzker, M.D., Fowler, M.W., Douglas, P.L., Chewathanakup, S. and Mahaudom, H., Experimental and modeling study of solid oxide fuel cell operating with syngas fuel. Journal of Power Sources, 161(1), pp. 308-322, 2006.

[11] Jiang, Y. and Virkar, A.V., Fuel composition and diluent effect on gas transport and performance of anode-supported sofcs. Journal of The Electrochemical Society, 150(7), pp. A942-A951, 2003.

[12] Singhal, S.C. and Kindall, K., High Temperature Solid Oxide Fuel Cells. Elsevier: Oxford, 2004.

[13] Hajimolana, S.A., Hussain, M.A., Daud, W.M.A.W., Soroush, M. and Shamiri, A., Mathematical modeling of solid oxide fuel cells: A review. Renew Sust Energ Rev, 15(4), pp. 1893-1917, 2011.

[14] Kemm, M., Dynamic Solid Oxide Fuel Cell Modelling for Non-steady State Simulation of System Applications. Doctoral dissertation, Lund University, 2006. 